\title{
Development of alkoxy styrylchromone derivatives for imaging of cerebral amyloid- $\beta$ plaques with SPECT
}

Takeshi Fuchigami ${ }^{{ }^{*}}$, Ayaka Ogawa ${ }^{\mathrm{a}}$, Yuki Yamashita ${ }^{\mathrm{a}}$, Mamoru Haratake ${ }^{\mathrm{a}, \mathrm{b}}$, Hiroyuki Watanabe $^{\mathrm{c}}$, Masahiro Ono ${ }^{\mathrm{c}}$, Masao Kawasaki ${ }^{\mathrm{a}}$, Sakura Yoshida ${ }^{\mathrm{a}}$, Morio Nakayama ${ }^{\mathrm{a}}$

${ }^{\text {a }}$ Department of Hygienic Chemistry, Graduate School of Biomedical Sciences, Nagasaki University, 1-14 Bunkyo-machi, Nagasaki 852-8521, Japan

${ }^{\mathrm{b}}$ Faculty of Pharmaceutical Sciences, Sojo University, 4-22-1 Ikeda, Kumamoto 860-0082, Japan

c Graduate School of Pharmaceutical Sciences, Kyoto University, 46-29 Yoshida Shimoadachi-cho, Sakyo-ku, Kyoto 606-8501, Japan.

*corresponding author:

Takeshi Fuchigami,

Graduate School of Biomedical Sciences, Nagasaki University, 1-14 Bunkyo-machi, Nagasaki 852-8521, Japan.

Tel.: +81-95-819-2443; 
Fax: +81-95-819-2443;

E-mail: t-fuchi@nagasaki-u.ac.jp

Morio Nakayama,

Graduate School of Biomedical Sciences, Nagasaki University, 1-14 Bunkyo-machi, Nagasaki 852-8521, Japan.

Tel.: +81-95-819-2441;

Fax: +81-95-819-2441;

E-mail: morio@nagasaki-u.ac.jp

\section{Abstract}

We report here the development of radioiodinated styrylchromone derivatives with alkoxy groups as single photon emission computed tomography (SPECT) imaging probes for cerebral amyloid- $\beta$ ( $\mathrm{A} \beta$ ) plaques. Among the derivatives, the methoxy derivative $\mathbf{1 4}$ and the dimethoxy derivative 15 displayed relatively high affinity for the $\mathrm{A} \beta(1-42)$ aggregates with Ki values of 22 and $46 \mathrm{nM}$, respectively. Fluorescent imaging demonstrated that $\mathbf{1 4}$ and $\mathbf{1 5}$ clearly labeled thioflavin-S positive $\mathrm{A} \beta$ plaques in the brain sections of $\mathrm{Tg} 2576$ transgenic mice. In the in vivo studies, $\left[{ }^{125} \mathrm{I}\right] \mathbf{1 4}$ and $\left[{ }^{125} \mathrm{I}\right] \mathbf{1 5}$ showed high initial brain uptake expressed as 
the percentage of the injected dose per gram (2.25\% and $2.49 \% \mathrm{ID} / \mathrm{g}$ at $2 \mathrm{~min}$, respectively) with favorable clearance $(0.12 \%$ and $0.20 \% \mathrm{ID} / \mathrm{g}$ at $180 \mathrm{~min}$, respectively) from the brain tissue of normal mice. Furthermore, in vitro autoradiography confirmed that $\left[{ }^{125} \mathrm{I}\right] \mathbf{1 5}$ binds thioflavin-S positive regions in $\mathrm{Tg} 2576$ mouse brain sections. The derivative $\mathbf{1 5}$ may be a potential scaffold for the development of in vivo imaging probes targeting $\mathrm{A} \beta$ plaques in the brain. In particular, further structural modifications are required to improve the compounds binding affinity for $\mathrm{A} \beta$.

Key words: Alzheimer's disease, amyloid- $\beta$ plaque, styrylchromone, single photon emission computed tomography (SPECT).

Alzheimer's disease (AD), which is the most common cause of dementia in the elderly, is characterized by the progressive decline of cognition including learning and memory ${ }^{1}$. It is estimated that the number of patients with $\mathrm{AD}$ will increase to over 100 million by the year 2050 and, for this reason, effective therapies need to be developed to prevent the collapse ofglobal health-care systems ${ }^{2}$. A $\beta$ plaques have been detected in patients prior to the appearance of the clinical symptoms of AD. This implies that the detection and early initiation of treatment targeting $\mathrm{A} \beta$ deposits could be an effective therapeutic option to improve the symptoms of AD patients in the early disease stage $e^{2,3}$. Nuclear medicine imaging techniques 
have been accepted as useful tools for the early detection of cerebral $\mathrm{A} \beta$ plaque deposits ${ }^{4}$. Numerous studies have reported the development of positron emission tomography (PET) and SPECT imaging probes of $\mathrm{A} \beta$ plaques in the living brain ${ }^{5-7}$. In particular, ${ }^{18} \mathrm{~F}$-flutemetamol, ${ }^{18} \mathrm{~F}$-florbetapir and ${ }^{18} \mathrm{~F}$-florbetaben have demonstrated highly correlated brain distribution patterns with post-mortem existence of $\mathrm{A} \beta$ plaques. Recently, these PET tracers were approved by the US Food and Drug Administration (FDA) for the specific detection of $\mathrm{A} \beta$ plaques inclinical practice ${ }^{8-10}$. In contrast, there are currently no effective SPECT probes for detecting $\mathrm{A} \beta$ plaques despite their convenience and widespread utilization. SPECT is widely available in most hospitals, and is generally less expensive, as compared to PET ${ }^{11,12}$. Accordingly, the development of clinically useful SPECT imaging probes for $\mathrm{A} \beta$ can facilitate and encourage the initial diagnosis of $\mathrm{AD}$ in elderly people. Previously, we have developed flavonoid derivatives such as flavones, chalcones, aurones, and styrylchromones as prospective $\mathrm{A} \beta$ imaging probes, although clinically available compounds have not yet been developed ${ }^{13-22}$. We found that radioiodinated styrylchromones (SCs) with amino groups $\left(\mathrm{NH}_{2}\right.$, $\mathrm{NHMe}$, and $\mathrm{NMe}_{2}$ ) bind to $\mathrm{A} \beta$ aggregates with high binding affinities. However, their initial uptake and washout from normal mice brain tissue were inadequate for in vivo imaging ${ }^{22}$. Therefore, we hypothesized that the structural modification of SCs may improve the in vivo brain distribution and thereby, provide useful $\mathrm{A} \beta$ imaging agents. Previously, we reported that radioiodinated flavonoids such as flavone, chalcone, and aurone derivatives with alkoxy 
groups at the $p$-position of the phenyl ring showed good initial brain uptake and washout from the normal brain without crucial decline in binding affinity for $\mathrm{A} \beta^{13,19,21}$. Therefore, we considered that the introduction of alkoxy groups to the structure of SCs could improve their in vivo brain distribution. For this reason, we designed new radioiodinated SCs derivatives, which have alkoxy groups introduced into the 2-phenyl ring of the original structure. We envisaged that this structural modification would enable their application in SPECT diagnosis.

The synthesis of the alkoxy SC derivatives is presented in Scheme 1. O-acylation of the 5'-bromo-2'-hydroxyacetophenone with the appropriate cinnamoyl chlorides provided phenyl cinnamates 1-3. The Baker-Venkataraman rearrangement of the phenyl cinnamates using $\mathrm{KOH}$ gave the corresponding 1,3-diketones 4-6. The treatment of these 1,3-diketones with a mixture of $\mathrm{H}_{2} \mathrm{SO}_{4}$ and $\mathrm{AcOH}$ led to their cyclodehydration yielding (E)-2-styrylchromones 7-9. These styrylchromones were converted to tributyltin derivatives 10-12 using a bromo-to-tributyltin exchange reaction catalyzed by $\operatorname{Pd}(0)$. The resulting tributyltin derivatives were reacted with iodine in $\mathrm{CHCl}_{3}$ to form the target iodo derivatives 13-15. Methoxy derivative 14 was converted to phenol derivative 16 by demethylation with $\mathrm{BBr}_{3}$ in $\mathrm{CH}_{2} \mathrm{Cl}_{2}$. Alkylation of $\mathbf{1 6}$ with ethylene chlorohydrin, ethylene glycol mono-2-chloroethyl ether, or 2-[2-(2-chloroethoxy)ethoxy]ethanolusing potassium carbonate resulted in oligoethyleneoxy derivatives $17, \mathbf{1 8}$, and 19 , respectively.

In vitro binding experiments to evaluate, the binding affinity of the SC derivatives for 
$\mathrm{A} \beta$ were performed. We used suspensions of $\mathrm{A} \beta(1-42)$ aggregates with ${ }^{125}$ I-labeled 4-dimethylamino-4'-iodo-styrylchromone (20), which showed high binding affinity for $\mathrm{A} \beta$ aggregates $\left(K_{d}=8.7 \mathrm{nM}\right)$ in our previous studies ${ }^{22}$. The inhibition constant $\left(K_{\mathrm{i}}\right)$ values of the SCs for the $\mathrm{A} \beta$ aggregates ranged from 21.9 to 553nM (Table 1). Derivative 13, which contained an unsubstituted 2-phenyl ring, displayed weak affinity for $\mathrm{A} \beta$ aggregates $\left(K_{\mathrm{i}}=198\right.$ $\mathrm{nM})$. In contrast, methoxy derivative $14\left(K_{\mathrm{i}}=21 \mathrm{nM}\right)$ showed a 9-fold improvement in binding affinity versus 13 , displaying comparable affinity to dimethylamino derivative $20\left(K_{\mathrm{i}}\right.$ $=22 \mathrm{nM}$ ). Accordingly, the presence of a methoxy group at $\mathrm{R}_{1}$ may have a crucial role in binding interactions with $\mathrm{A} \beta$ aggregates. Dimethoxy derivative 15 had a reasonable binding affinity $(\mathrm{Ki}=46 \mathrm{nM})$, suggesting that the introduction of a methoxy group at the $\mathrm{R}_{2}$ position can retain binding affinity. However, introduction of a hydroxyl group at the $\mathrm{R}_{1}$ position did not improve the binding affinity. Indeed, hydroxyl derivative $\mathbf{1 6}$ displayed a negligible $\mathrm{A} \beta$ binding affinity $\left(K_{\mathrm{i}}=121 \mathrm{nM}\right)$. The oligoethyleneoxy derivatives 17-19 exhibited reduced binding affinities $\left(K_{\mathrm{i}}=415-553 \mathrm{nM}\right)$, which were over 20-fold lower than 14 . In our previous study, the introduction of oligoethyleneoxy groups to the phenyl ring of radioiodinated aurones did not considerably alter $\mathrm{A} \beta$ aggregate binding ${ }^{21}$. In this study, we observed the opposite effect, in that the presence of oligoethyleneoxy groups on the 2-phenyl ring of the SCs clearly had a deleterious effect on $\mathrm{A} \beta$ aggregate binding affinity. These facts suggest that SCs and aurones may exhibit different binding interactions with $\mathrm{A} \beta$ aggregates, although the 
mechanisms remain largely unclear.

Based on the in vitro results, we selected 14 and $\mathbf{1 5}$ for further biological evaluation. Fluorescence imaging experiments with the SCs were performed using brain slices from a transgenic mouse ( $\mathrm{Tg} 2576$ ) model of $\mathrm{A} \beta$ deposition. A number of fluorescence spots denoting derivatives 14 and 15 were observed in the mouse brain slices (Figs. 2A and B). The labeling patterns of these compounds corresponded to the fluorescence signals obtained with thioflavin-S staining (Figs. 2C and D). In contrast, there was no significant fluorescence for 14 and 15 in the brain slices from wild-type mice (Figs. 2E and F). There was no marked autofluorescence detected in any brain slices (data not shown). These results indicate that $\mathbf{1 4}$ and $\mathbf{1 5}$ have specific binding potential to $\mathrm{A} \beta$ plaques in the mouse brain.

For the biodistribution study and in vitro autoradiography, ${ }^{125}$ I-labeled SC derivatives ([ $\left.\left.{ }^{125} \mathrm{I}\right] 14, \quad\left[{ }^{125} \mathrm{I}\right] 15\right)$ were synthesized by an iododestannylation reaction of tributyltin derivatives (11 and 12) with hydrogen peroxide as an oxidant (Scheme 2). Using HPLC systems, the radioligands were purified, and the radiochemical qualities of these ligands were analyzed by co-injection of non-radioactive compounds. The radioiodinated products were obtained in radiochemical yields of $40-75 \%$ with a radiochemical purity of $>95 \%$. Clinically available SPECT imaging probes for the $\mathrm{A} \beta$ plaque should show a high initial brain uptake and rapid clearance from non-target regions in the brain. Therefore, biodistribution studies of $\left[{ }^{125} \mathrm{I}\right] 14$ and $\left[{ }^{125} \mathrm{I}\right] \mathbf{1 5}$ were conducted in normal mice and expressed as \% of injected dose per 
gram (\%ID/g) (Table 2). The compounds $\left[{ }^{125} \mathrm{I}\right] \mathbf{1 4}$ and $\left[{ }^{125} \mathrm{I}\right] \mathbf{1 5}$ exhibited a high initial brain uptake (2.3\% and $2.5 \% \mathrm{ID} / \mathrm{g}$ at $2 \mathrm{~min}$, respectively) and a favorable brain clearance $(0.1 \%$ and $0.2 \% \mathrm{ID} / \mathrm{g}$ at $180 \mathrm{~min}$, respectively). The brain $_{2 \mathrm{~min}} / \mathrm{brain}_{60 \mathrm{~min}}$ ratio of ${ }^{18} \mathrm{~F}$ has been used as an index of brain washout ${ }^{23,24}$. The brain ${ }_{2 \min } /$ brain $_{60 \mathrm{~min}}$ ratio of clinically used $\left[{ }^{18} \mathrm{~F}\right]$ Florbetapir $\left(\left[{ }^{18} \mathrm{~F}\right] \mathrm{AV}-45\right)$ and $\left[{ }^{18} \mathrm{~F}\right]$ Florbetaben $\left(\left[{ }^{18} \mathrm{~F}\right] \mathrm{BAY} 94-917218\right)$ was reported to be $3.8^{23}$ and $4.8^{25}$, respectively. Since the brain $_{2 \mathrm{~min}} /$ brain $_{60 \mathrm{~min}}$ ratio of $\left[{ }^{125} \mathrm{I}\right] \mathbf{1 4}$ and $\left[{ }^{125} \mathrm{I}\right] \mathbf{1 5}$ was calculated to be 4.5 and 3.3, respectively, the washout index of these $\left[{ }^{125} \mathrm{I}\right] \mathrm{SC}$ derivatives seems to be comparable to the aforementioned PET probes. Additionally, because the half-life of radioactive iodine ${ }^{123} \mathrm{I}$, used for SPECT, is much longer than that of ${ }^{18} \mathrm{~F}$ (13.2 h vs $110 \mathrm{~min}$ ), the brain $_{2 \min } /$ brain $_{180 \min }$ ratio can be used as another index of brain washout in this study. The brain $_{2 \min } /$ brain $_{180 \min }$ ratios of $\left[{ }^{125} \mathrm{I}\right] \mathbf{1 4}$ and $\left[{ }^{125} \mathrm{I}\right] \mathbf{1 5}$ were 18.8 and 12.5 , respectively, indicating that these two ${ }^{125}$ I-labeled SC derivatives have promising in vivo pharmacokinetics. Furthermore, the collective in vivo results suggested that the washout of $\left[{ }^{125} \mathrm{I}\right] \mathbf{1 4}$ from the normal brain tissue was faster than that of $\left[{ }^{125} \mathrm{I}\right] \mathbf{1 5}$. Both $\left[{ }^{125} \mathrm{I}\right] \mathbf{1 4}$ and $\left[{ }^{125} \mathrm{I}\right] \mathbf{1 5}$ demonstrated increased radioactivity in the stomach over time, and peaked at 5.0\% and 5.2\% ID/g at 60 min, respectively, suggesting that these SCs were gradually deionidated in vivo. Since brain uptake of these tracers rapidly declined with time, it is unlikely that the metabolites could easily penetrate the blood brain barrier. Consistent with our previous study ${ }^{22}$, relatively low initial brain uptake and high brain retention of the dimethylamino derivative $\left[{ }^{125} \mathrm{I}\right] 20(1.20 \%$ 
$\mathrm{ID} / \mathrm{g}$ at $2 \mathrm{~min}$ and $0.38 \% \mathrm{ID} / \mathrm{g}$ at $180 \mathrm{~min}$ ) was observed, compared with the methoxy derivatives. It is reported that radiotracers with a low molecular weight $(<500 \mathrm{Da})$ and a moderate lipophilicity $\left(\log D_{7.4}\right.$ values, $\left.2.0-3.5\right)$ show optimal passive brain entry in vivo ${ }^{26,27}$. Although the molecular weights of the ${ }^{125}$ I-labeled compounds in this study are all within the specified range (Table 2), the most lipophilic $\left[{ }^{125} \mathrm{I}\right] 20$ showed a relatively low blood-brain barrier permeability. Taken together, these results indicate that the substitution of a dimethylamino group with methoxy groups at the 2-phenyl ring position of the SCs structure improves its brain distribution for in vivo imaging.

To further characterize $\left[{ }^{125} \mathrm{I}\right] \mathbf{1 4}$ and $\left[{ }^{125} \mathrm{I}\right] \mathbf{1 5}$ as possible imaging probes for specifically targeting $\mathrm{A} \beta$ plaques, in vitro autoradiography was performed using brain sections from the Tg2576 mice. Although some $\left[{ }^{125} \mathrm{I}\right] \mathbf{1 4}$ spots in the brain slices corresponded to thioflavin-S stained regions, the overall $\left[{ }^{125} \mathrm{I}\right] \mathbf{1 4}$ image was inconsistent with the existence of $\mathrm{A} \beta$ plaques (Fig. 3A and 3C). In contrast, clear $\left[{ }^{125} \mathrm{I}\right] \mathbf{1 5}$ autoradiographic images were observed in the thioflavin-S positive regions (Fig. 3B and 3D). The discrepancy between the fluorescence and autoradiographic images of these SC derivatives could have been caused by the different concentration of the compounds. The concentration of the SCs was $100 \mu \mathrm{M}$ for the fluorescence staining while only $0.3 \mathrm{nM}$ of ${ }^{125}$ I labeled SCs was used in the autoradiography studies. It is unclear why only the $\left[{ }^{125} \mathrm{I}\right] 15$ displayed a clear autoradiograph for $\mathrm{A} \beta$ plaques, despite the fact that derivative $\mathbf{1 5}$ possesses a lower binding affinity for the $\mathrm{A} \beta$ aggregates 
than 14 (Table 1). Several factors may have contributed to these results, including the selectivity for $\mathrm{A} \beta$ plaques over other brain components, degree of nonspecific binding, and conformation differences between the $\mathrm{A} \beta$ aggregates and $\mathrm{A} \beta$ plaques in the brain of $\operatorname{Tg} 2576$ mice. Regardless, the $\left.{ }^{[25} \mathrm{I}\right] 15$ may be a potential lead compound for the development of in vivo imaging probes for $\mathrm{A} \beta$ plaques in the brain. Further structural modification of the SC derivatives can provide promising $\mathrm{A} \beta$ imaging probes.

In conclusion, we demonstrated that radioiodinated styrylchromone derivatives with methoxy groups had preferable pharmacokinetics for in vivo imaging without significant reduction in binding affinity for the $\mathrm{A} \beta$ aggregates. In particular, both fluorescent imaging and autoradiography showed that the dimethoxy derivative $\left[{ }^{125} \mathrm{I}\right] \mathbf{1 5}$ labeled the thioflavin-S positive $\mathrm{A} \beta$ plaques in sections of the $\mathrm{Tg} 2576$ mouse brain. Further structural modifications based on derivative $\mathbf{1 5}$ may facilitate the development of clinically useful $\mathrm{A} \beta$ imaging probes.

\section{Acknowledgments}

Financial support was provided by a Grant-in-Aid for Scientific Research (B) (Grant No. 21390348) from Japan Society for the Promotion of Science (JSPS).

\section{References}

1. Querfurth, H. W.; LaFerla, F. M. N. Engl. J. Med. 2010, 362, 329. 
2. Karran, E.; Mercken, M.; De Strooper, B. Nat. Rev. Drug. Discov. 2011, 10, 698.

3. Selkoe, D. J.Physiol. Rev. 2001, 81, 741.

4. Shokouhi, S.; Claassen, D.; Riddle, W. J.Alzheimers. Dis. Parkinsonism. 2014, 4, 143.

5. Kung, H. F.; Choi, S. R.; Qu, W.; Zhang, W.; Skovronsky, D.J. Med. Chem. 2010,53, 933.

6. Ono, M.; Saji, H. J. Pharmacol. Sci. 2012, 118, 338.

7. Yang, Y.; Cui, M.Eur. J. Med. Chem. 2014, 87, 703.

8. Vandenberghe, R.; Adamczuk, K.; Dupont, P.; Laere, K. V.; Chételat, G. Neuroimage Clin. 2013, 2, 497.

9. Williams, S.C.P. Nat. Med. 2013, 19, 1551.

10. Senda, M.; Sasaki, M.; Yamane, T.; Shimizu, K.; Patt, M.; Barthel, H.; Sattler, B.; Nagasawa, T.; Schultze-Mosgau, M.; Aitoku, Y.; Dinkelborg, L.; Sabri, O. Eur. J. Nucl. Med. Mol. Imaging. 2014, 42, 89.

11. Mariani, G.; Bruselli, L.; Kuwert, T.; Kim, E. E.; Flotats, A.; Israel, O.; Dondi, M.; Watanabe, N. Eur. J. Nucl. Med. Mol. Imaging. 2010, 37, 1959.

12. Adak, S.; Bhalla, R.; Raj, K. K. V.; Mandal, S.; Pickett, R.; Luthra, S. K. Radiochim. Acta. 2012, 100, 95.

13. Ono, M.; Yoshida, N.; Ishibashi, K.; Haratake, M.; Arano, Y.; Mori, H.; Nakayama, M. J. Med. Chem. 2005, 48, 7253. 
14. Ono, M.; Watanabe, R.; Kawashima, H.; Kawai, T.; Watanabe, H.; Haratake, M.; Saji, H.; Nakayama, M. Bioorg. Med. Chem. 2009, 17, 2069.

15. Ono, M.; Hori, M.; Haratake, M.; Tomiyama, T.; Mori, H.; Nakayama, M. Bioorg. Med. Chem. 2007, 156388.

16. Ono, M.; Haratake, M.; Mori, H.; Nakayama, M. Bioorg. Med. Chem. 2007, 15, 6802.

17. Ono, M.; Watanabe, R.; Kawashima, H.; Cheng, Y.; Kimura, H.; Watanabe, H.; Haratake, M.; Saji, H.; Nakayama, M. J. Med. Chem. 2009, 52, 6394.

18. Ono, M.; Ikeoka, R.; Watanabe, H.; Kimura, H.; Fuchigami, T.; Haratake, M.; Saji, H.; Nakayama, M. ACS Chem. Neurosci. 2010, 1, 598.

19. Fuchigami, T.; Yamashita, Y.; Haratake, M.; Ono, M.; Yoshida, S.; Nakayama, M. Bioorg. Med. Chem. 2014, 22, 2622.

20. Ono, M.; Maya, Y.; Haratake, M.; Ito, K.; Mori, H.; Nakayama, M. Biochem. Biophys. Res. Commun. 2007, 361, 116.

21. Maya, Y.; Ono, M.; Watanabe, H.; Haratake, M.; Saji, H.; Nakayama, M. Bioconjug. Chem. 2009, 20, 95.

22. Ono, M.; Maya, Y.; Haratake, M.; Nakayama, M. Bioorg. Med. Chem. 2007, 15, 444.

23. Zhang, W.; Oya, S.; Kung, M. P.; Hou, C.; Maier, D. L.; Kung, H. F. Nucl. Med. Biol. 2005, 32, 799.

24. Ono, M.; Cheng, Y.; Kimura, H.; Cui, M.; Kagawa, S.; Nishii, R.; Saji, H. J. Med. Chem. 
2011, 54, 2971.

25. Zhang, W.; Kung, M. P.; Oya, S.; Hou, C.; Kung, H. F. Nucl. Med. Biol. 2007, 34, 89.

26. Pike, V. W. Trends. Pharmacol. Sci. 2009, 30, 431.

27. Waterhouse, R. N. Mol. Imaging. Biol. 2003, 5, 376. 
Scheme 1. Synthesis of styrylchromone derivatives.
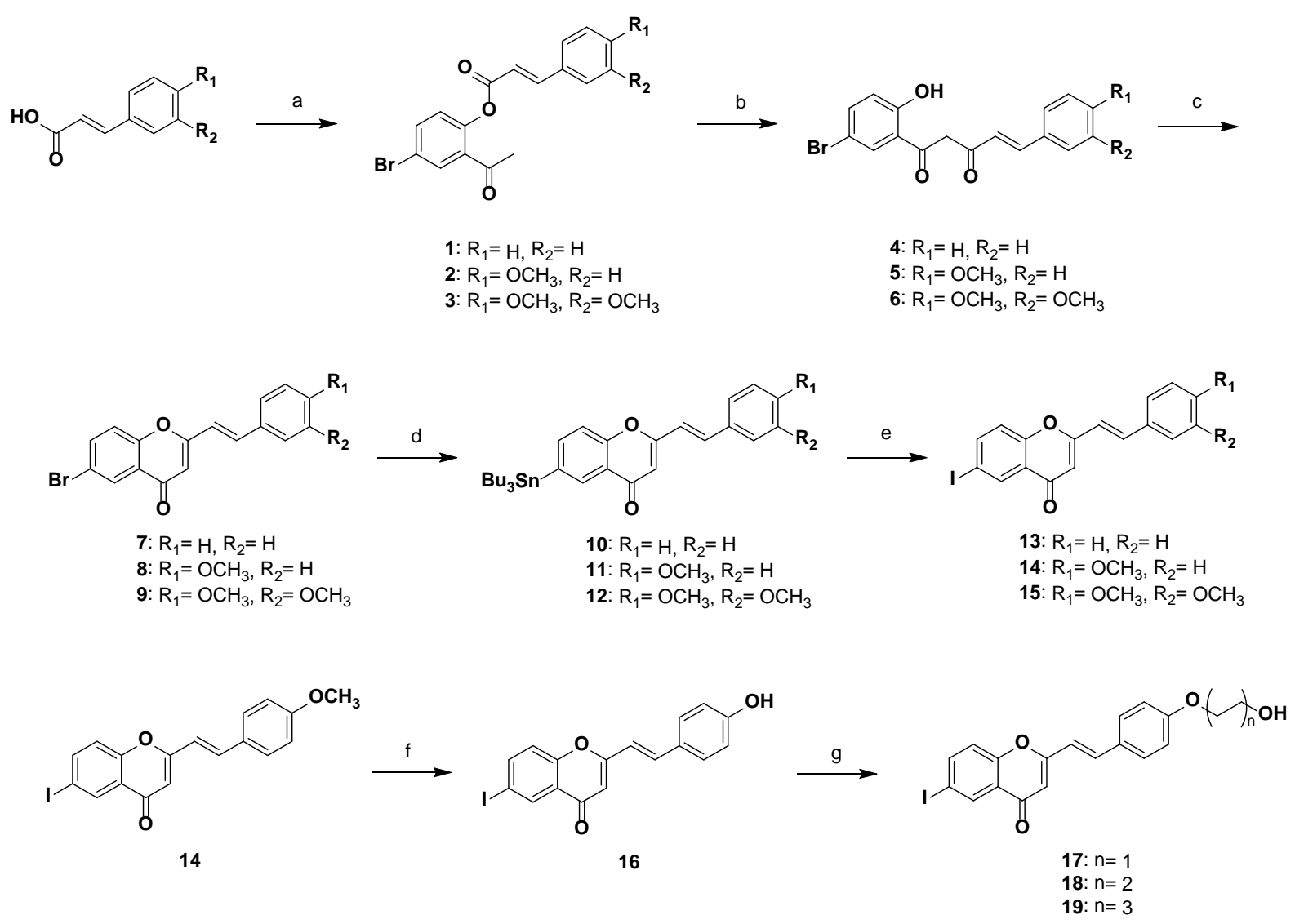

Reagents and conditions: (a) 1) $\mathrm{SOCl}_{2}$, DMF, reflux 1 h, 2) 5'-Bromo-2'hydroxyacetophenone, pyridine, reflux, 3 h; (b) pyridine, $\mathrm{KOH}$, reflux, 1h; (c) $\mathrm{H}_{2} \mathrm{SO}_{4}, \mathrm{AcOH}$, reflux, 1 h then r.t., 1h; (d) $\left(\mathrm{SnBu}_{3}\right)_{2}, \mathrm{Pd}\left(\mathrm{PPh}_{3}\right)_{4}, \mathrm{Et}_{3} \mathrm{~N}$, dioxane, reflux, 7 h, (e) I, $\mathrm{CHCl}_{3}$, r.t., 30 min (f) $\mathrm{CH}_{2} \mathrm{Cl}_{2}, \mathrm{BBr}_{3}$, r.t., 24 h; (g) $\mathrm{H}\left(\mathrm{OCH}_{2} \mathrm{CH}_{2}\right)_{\mathrm{n}} \mathrm{Cl}, \mathrm{K}_{2} \mathrm{CO}_{3}, \mathrm{DMF}$. 
Scheme 2. Radiosynthesis of ${ }^{125}$ I-labeled styrylchromone derivatives.

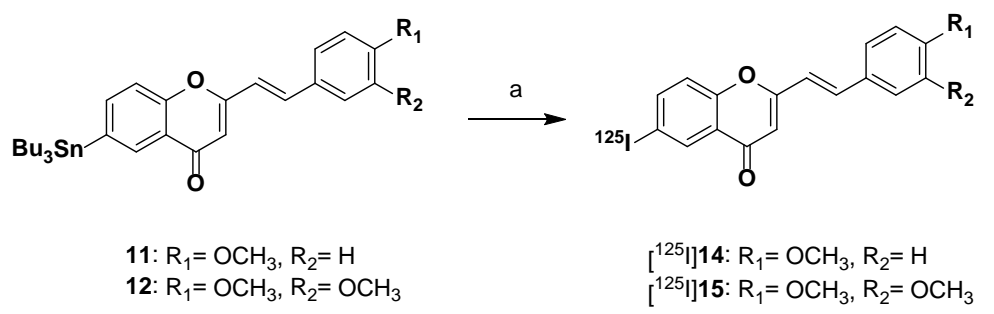

Reagents and conditions: (a) $\left[{ }^{125} \mathrm{I}\right] \mathrm{NaI}, \mathrm{H}_{2} \mathrm{O}_{2}, \mathrm{HCl}, \mathrm{EtOH}, 3$ min. 
Table 1. Inhibition constant $\left(K_{\mathrm{i}}\right)$ for $\mathrm{A} \beta$ (1-42) aggregates and $\log P$ values of styrylchromone derivatives.<smiles>[R2]c1ccc(/C=C/c2cc(=O)c3cc(I)ccc3o2)cc1[R2]</smiles>

$$
\begin{aligned}
& \text { 13: } \mathrm{R}_{1}=\mathrm{H}, \mathrm{R}_{2}=\mathrm{H} \\
& \text { 14: } \mathrm{R}_{1}=\mathrm{OMe}, \mathrm{R}_{2}=\mathrm{H} \\
& \text { 15: } \mathrm{R}_{1}=\mathrm{OMe}, \mathrm{R}_{2}=\mathrm{OMe} \\
& \text { 16: } \mathrm{R}_{1}=\mathrm{OH}, \mathrm{R}_{2}=\mathrm{H} \\
& \text { 17: } \mathrm{R}_{1}=\mathrm{OCH}_{2} \mathrm{CH}_{2} \mathrm{OH}, \mathrm{R}_{2}=\mathrm{H} \\
& \text { 18: } \mathrm{R}_{1}=\left(\mathrm{OCH}_{2} \mathrm{CH}_{2}\right)_{2} \mathrm{OH}, \mathrm{R}_{2}=H \\
& \text { 19: } \mathrm{R}_{1}=\left(\mathrm{OCH}_{2} \mathrm{CH}_{2}\right)_{3} \mathrm{OH}, \mathrm{R}_{2}=H \\
& \text { 20: } \mathrm{R}_{1}=\mathrm{N}\left(\mathrm{CH}_{3}\right)_{2}, \mathrm{R}_{2}=H
\end{aligned}
$$

\begin{tabular}{|c|c|c|c|c|c|}
\hline Compounds & \multicolumn{3}{|c|}{$\mathrm{Ki}^{\mathrm{a}}(\mathrm{nM})$} & Mw & $\log \mathrm{P}^{\mathrm{b}}$ \\
\hline 13 & 198 & \pm & 48.0 & 374.1 & - \\
\hline 14 & 21.9 & \pm & 5.10 & 404.2 & 2.15 \\
\hline 15 & 45.5 & \pm & 10.7 & 434.2 & 2.14 \\
\hline 16 & 121 & \pm & 20.8 & 390.2 & 1.87 \\
\hline 17 & 446 & \pm & 100 & 434.2 & - \\
\hline 18 & 415 & & 64.5 & 478.3 & - \\
\hline 19 & 553 & & 135 & 522.3 & - \\
\hline 20 & 21.8 & \pm & 3.35 & 417.3 & $2.65^{c}$ \\
\hline
\end{tabular}


${ }^{a}$ Inhibition constant of styrylchromone derivatives were determined using $\left[{ }^{125} \mathrm{I}\right] \mathbf{2 0}$ as the ligand in $\mathrm{A} \beta$ aggregates. Each value (mean \pm SEM) was determined by 3-6 independent experiments.

b The partition coefficient between $n$-octanol and sodium phosphate buffer at $\mathrm{pH} 7.4$ was determined by a conventional flask shaking method $(n=3)$.

${ }^{\mathrm{c}}$ The $\log P$ values have been reported in our previous studies ${ }^{22}$. 
Table 2. Biodistribution of radioactivity after i.v. injection of ${ }^{125} \mathrm{I}$ labeled styrylchromone derivatives in normal mice.

\begin{tabular}{|c|c|c|c|c|c|}
\hline \multirow[b]{2}{*}{ Organ } & \multicolumn{5}{|c|}{ Time after injection (min) } \\
\hline & 2 & 30 & 60 & 120 & 180 \\
\hline & \multicolumn{5}{|c|}{$\left[{ }^{125} \mathrm{I}\right] 14$} \\
\hline Blood & $2.22(0.31)$ & $0.76(0.09)$ & $0.56(0.13)$ & $0.36(0.08)$ & $0.29(0.04)$ \\
\hline Liver & $20.90(3.32)$ & 14.72 (3.73) & 9.10 (2.58) & 6.53 (3.63) & 3.38 (0.59) \\
\hline Kidney & 10.06 (1.94) & $4.50(1.55)$ & $2.20(0.41)$ & $1.28(0.40)$ & $0.85(0.12)$ \\
\hline Intestine & $1.70(0.67)$ & $10.41(3.60)$ & $18.57(7.07)$ & $22.64(6.14)$ & $18.82(3.81)$ \\
\hline Spleen & $3.81(1.11)$ & $1.19(0.20)$ & $0.82(0.17)$ & $0.70(0.26)$ & $0.55(0.32)$ \\
\hline Lung & $6.12(1.61)$ & $1.77(0.33)$ & $1.17(0.28)$ & $0.78(0.18)$ & $0.60(0.19)$ \\
\hline Stomach & $0.96(0.26)$ & $1.22(0.88)$ & $2.58(2.09)$ & $5.03(4.15)$ & $4.19(1.37)$ \\
\hline Pancreas & $5.26(0.84)$ & $1.44(0.22)$ & $1.06(0.44)$ & $0.82(0.74)$ & $0.68(0.72)$ \\
\hline Heart & $5.50(1.08)$ & $1.09(0.08)$ & $0.67(0.15)$ & $0.37(0.10)$ & $0.26(0.08)$ \\
\hline \multirow[t]{2}{*}{ Brain } & $2.25(0.38)$ & $1.00(0.12)$ & $0.56(0.11)$ & $0.23(0.06)$ & $0.12(0.02)$ \\
\hline & & & {$\left[{ }^{125} \mathrm{I}\right] 15$} & & \\
\hline Blood & $3.42(0.32)$ & $1.25(0.16)$ & $0.74(0.10)$ & $0.61(0.14)$ & $0.33(0.05)$ \\
\hline Liver & 15.07 (1.39) & 7.42 (1.46) & 4.98 (1.39) & $3.50(0.82)$ & $4.26(0.80)$ \\
\hline
\end{tabular}




$\begin{array}{lccccc}\text { Kidney } & 12.28(1.43) & 4.74(0.70) & 2.37(0.33) & 1.51(0.18) & 1.09(0.20) \\ \text { Intestine } & 1.71(0.47) & 12.19(4.91) & 15.93(8.64) & 27.37(4.85) & 23.16(3.95) \\ \text { Spleen } & 4.86(0.69) & 1.62(0.31) & 1.04(0.16) & 0.80(0.49) & 1.33(1.19) \\ \text { Lung } & 7.00(0.99) & 2.31(0.31) & 1.46(0.18) & 0.95(0.11) & 1.68(2.48) \\ \text { Stomach } & 1.39(0.18) & 2.75(2.17) & 1.77(0.53) & 5.15(3.29) & 3.67(2.82) \\ \text { Pancreas } & 7.17(1.62) & 2.95(0.90) & 1.13(0.17) & 0.76(0.34) & 0.42(0.20) \\ \text { Heart } & 6.96(0.93) & 1.68(0.23) & 0.96(0.13) & 0.52(0.08) & 0.32(0.08) \\ & & & & & \\ \text { Brain } & 2.49(0.39) & 1.39(0.16) & 0.76(0.12) & 0.36(0.05) & 0.20(0.12)\end{array}$

$\begin{array}{lccccc} & & & & \\ & & & & \\ \text { Blood } & 2.24(0.43) & 1.20(0.17) & 1.02(0.16) & 1.07(0.19) & 1.09(0.29) \\ \text { Liver } & 12.3(2.65) & 8.36(2.01) & 5.84(1.18) & 7.46(2.61) & 4.36(1.29) \\ \text { Kidney } & 8.68(2.05) & 3.36(1.25) & 1.59(0.66) & 1.35(0.55) & 1.37(0.41) \\ \text { Intestine } & 1.20(0.48) & 11.83(2.26) & 9.90(5.68) & 13.43(5.52) & 10.03(2.58) \\ \text { Spleen } & 3.88(1.94) & 2.65(0.45) & 1.82(0.45) & 2.01(0.89) & 2.04(0.29) \\ \text { Lung } & 8.83(2.51) & 3.85(0.69) & 2.54(0.82) & 2.27(0.55) & 1.96(0.89) \\ \text { Stomach } & 1.01(0.31) & 1.88(0.79) & 1.79(0.66) & 3.15(1.46) & 3.38(2.68) \\ \text { Pancreas } & 3.37(0.59) & 1.44(0.58) & 0.84(0.14) & 0.81(0.31) & 0.59(0.21) \\ \text { Heart } & 5.51(1.33) & 1.26(0.31) & 0.66(0.13) & 0.63(0.14) & 0.64(0.17)\end{array}$




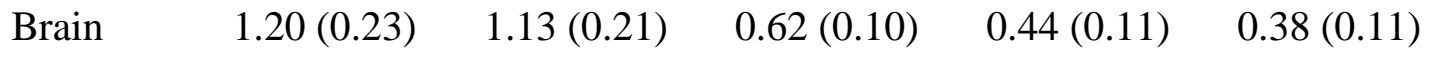

Each value represents mean (SD) for 5 or 6 mice at each interval. 


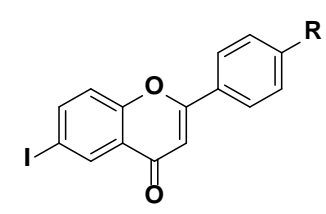

Flavones

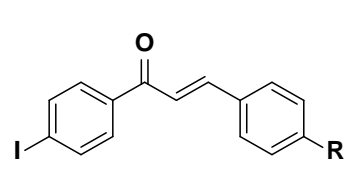

Chalcones

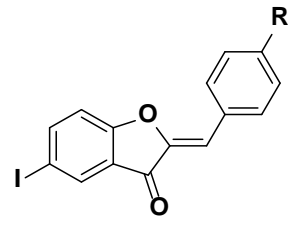

Aurones

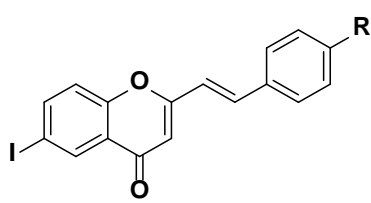

Styrylchromones

$\mathrm{R}=\mathrm{NMe}_{2}, \mathrm{NHMe}, \mathrm{NH}_{2}, \mathrm{OMe}, \mathrm{OH}$

Figure 1. Chemical structures of flavonoid derivatives reported as $\mathrm{A} \beta$ imaging probes. 

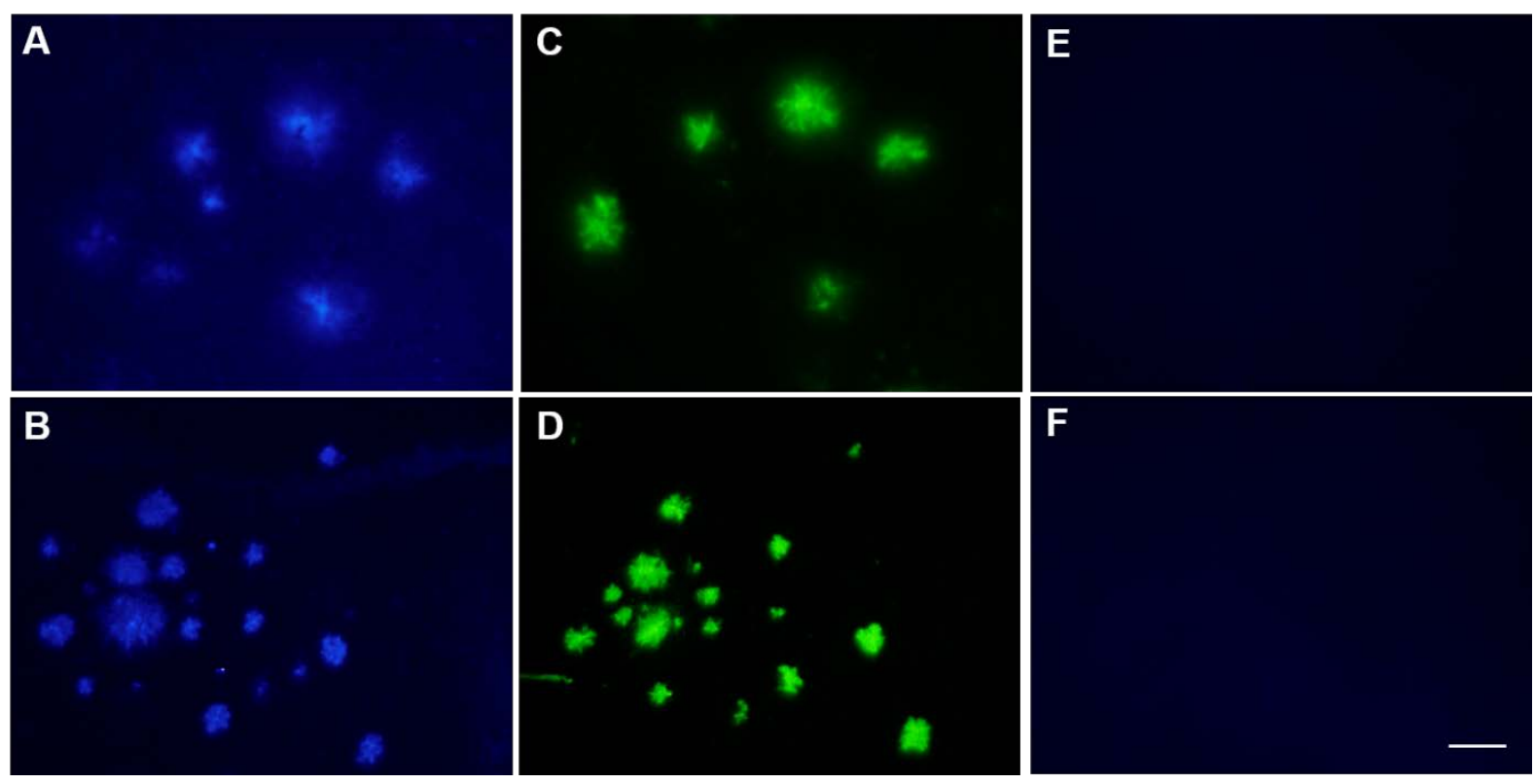

Figure 2. Neuropathological staining of styrylchromone derivatives 14 (A) and 15 (B) in 10 $\mu \mathrm{m}$ sections of $\operatorname{Tg} 2576$ mice brain. Labeled plaques were confirmed by staining of the adjacent sections with thioflavin-S (C and D). Fluorescence images of 14 (E) and $15(F)$ in the age-matched control mouse brain sections. Scale bar $=50 \mu \mathrm{m}$. 

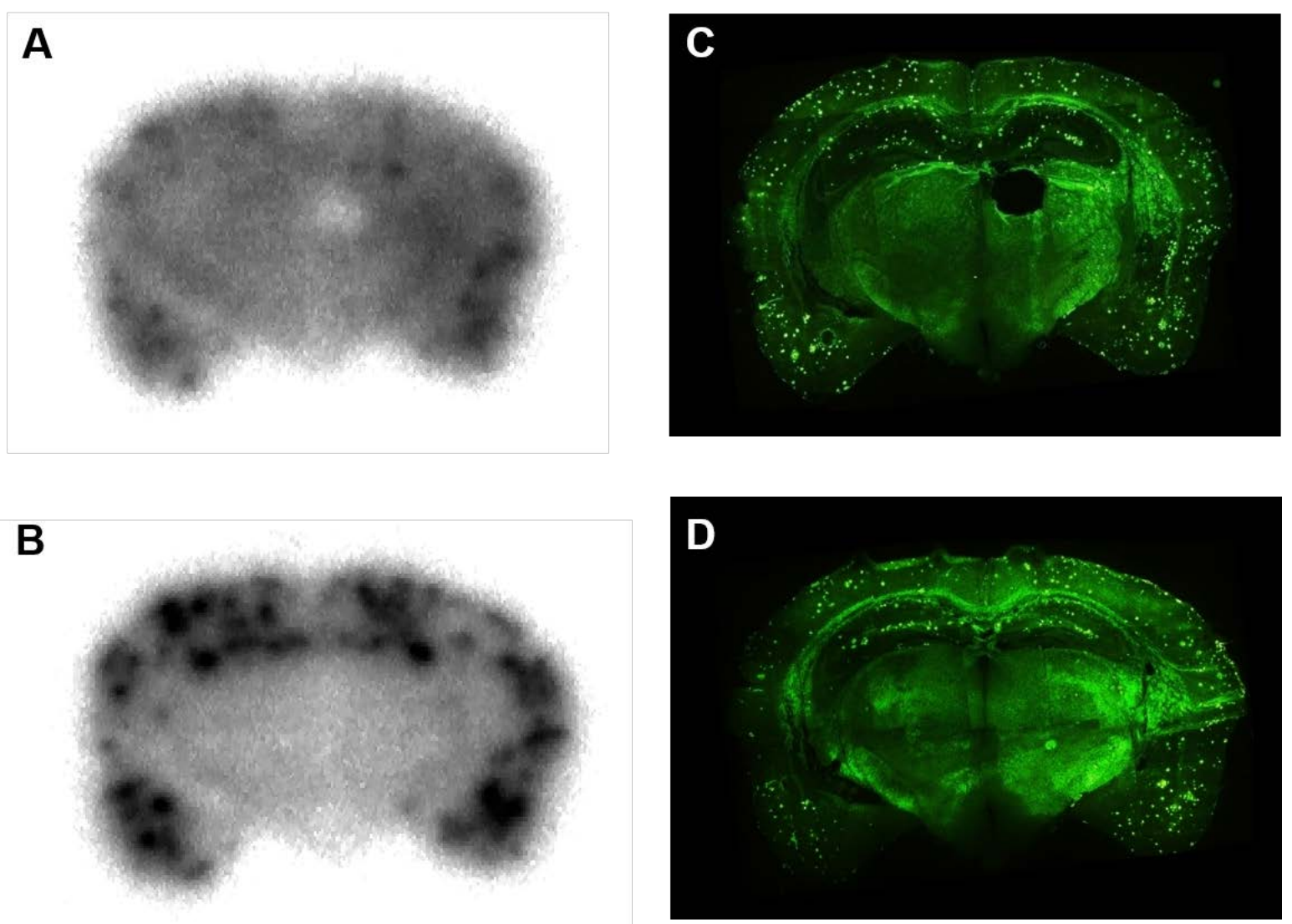

Figure 3. In vitro autoradiograms of styrylchromone derivatives $\left[{ }^{125} \mathrm{I}\right] \mathbf{1 4}(\mathrm{A})$ and $\left[{ }^{125} \mathrm{I}\right] \mathbf{1 5}$ (B) in the brain sections of $\mathrm{Tg} 2576$ mouse brain. Fluorescence images of thioflavin-S in the adjacent section (C and D). 